\title{
Modified Cotton Sponge with Bio-Based Polybenzoxazine for Plasticizer
}

\author{
Absorption and Oil-Water Separation \\ Thirukumaran Periyasamy ${ }^{\mathrm{a}}$, Shakila Parveen Asrafalia ${ }^{\mathrm{a}}$, Rajesh Haldhar ${ }^{\mathrm{a}}$, Santhamoorthy \\ Madhappan $^{\mathrm{a}}$, Ramkumar Vanaraj ${ }^{\mathrm{a}}$, Chaitany Jayprakash Raorane ${ }^{\mathrm{a}}$, Seong-Cheol Kimª,* \\ ${ }^{1}$ Authors contributed equally to this work. \\ aSchool of Chemical Engineering, Yeungnam University, Gyeongsan 38541, Republic of \\ Korea.
}

\section{Supporting Information}

\section{Instrumentation methods}

Fourier transform infrared (FT-IR) spectra were obtained with a Perkin Elmer MB3000 FTIR spectrometer. The spectra were obtained at a resolution of $4 \mathrm{~cm}^{-1}$ in the IR range of $400-4000 \mathrm{~cm}^{-1}$. Samples were prepared by grinding with $\mathrm{KBr}$ and compressed to form discs. Nuclear magnetic resonance (NMR) spectra were recorded by using an Agilent NMR, VNS600 at a proton frequency of $600 \mathrm{MHz}$ for ${ }^{1} \mathrm{H}-\mathrm{NMR}$ and at a carbon frequency of 150 $\mathrm{MHz}$ for ${ }^{13} \mathrm{C}-\mathrm{NMR}$. Solutions were prepared by dissolving the samples in $\mathrm{CDCl}_{3}$. XPS spectra were achieved using a K-Alpha (Thermo Scientific). CasaXPS software was used for the deconvolution of the high-resolution XPS spectra. Differential Scanning Calorimetry was performed in a TA instrument Q10 model using 5-10 $\mathrm{mg}$ of the sample at a heating rate of 10 ${ }^{\circ} \mathrm{C} \min ^{-1}$ in a $\mathrm{N}_{2}$ atmosphere. The morphology of the material was examined by scanning electron microscopy (FESEM, Hitachi S-4800) at an accelerating voltage of $30 \mathrm{kV}$. Contact angle measurements were taken using contact angle meter OCA 20 model. Drops were placed on the sample with DI water and their average contact angle was measured. Mechanical properties of cross-linked films were evaluated under uniaxial tension on an Instron E300LT, Universal Tester. Five specimens for each composition were tested at ambient temperature 
using $1 \mathrm{~mm} / \mathrm{min}$ as cross-head speed and the average value was reported. The reported modulus values were calculated from the slope of the stress-strain curve at $1 \%$ strain.

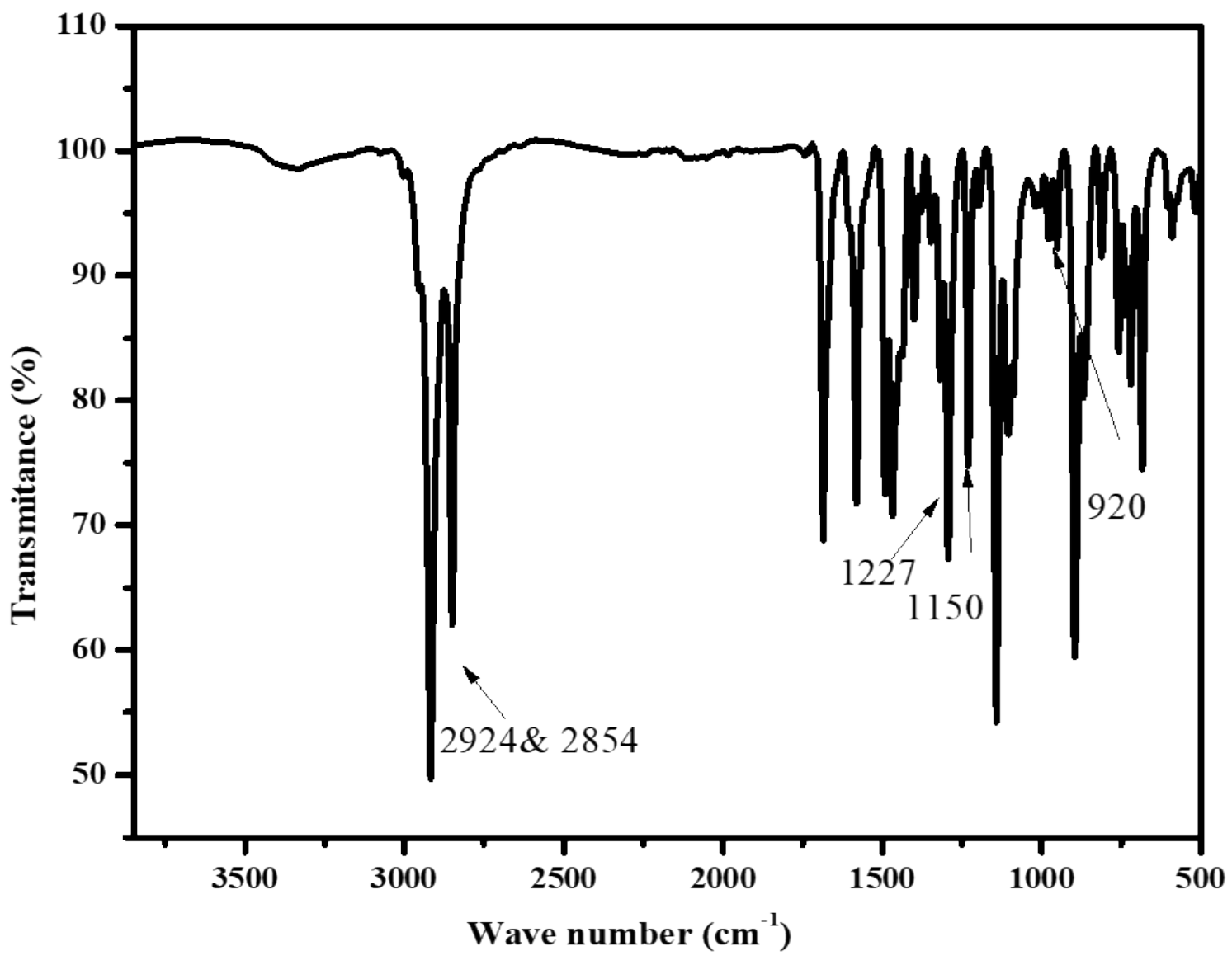

Figure S1. FT-IR spectrum of Eu-St Bzo monomer 


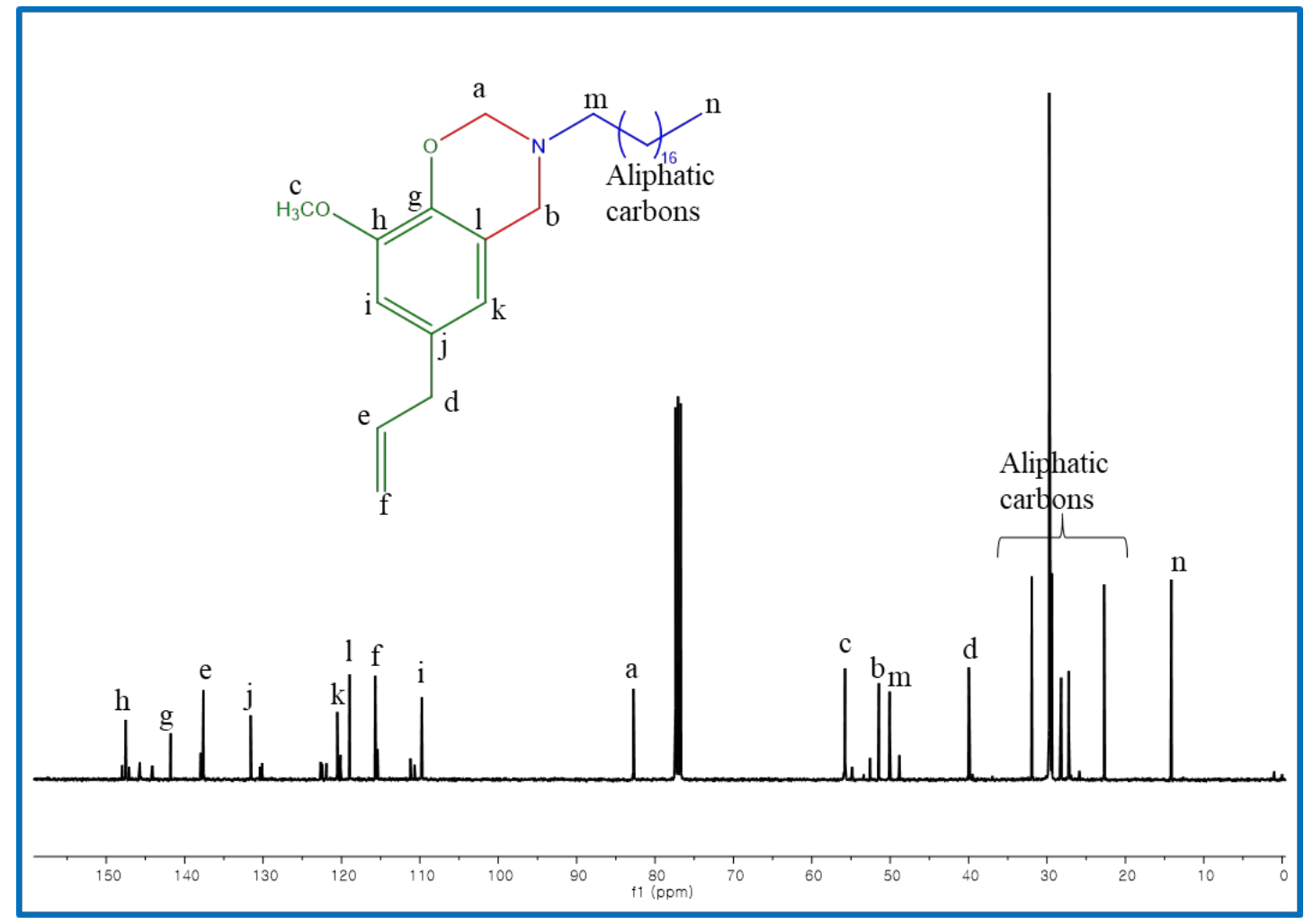

Figure S2. ${ }^{13} \mathrm{C}-\mathrm{NMR}$ spectrum of Eu-St Bzo monomer 